\title{
DRYING BEHAVIOUR OBSERVATIONS FOR WOOD CHIPS OF GRADE EN14961
}

\author{
Baibhaw Kumar \\ PhD Student, Institute of Energy Engineering and Chemical Machinery, University of Miskolc \\ 3515 Miskolc, Miskolc-Egyetemváros, e-mail: vegybk@uni-miskolc.hu \\ Gábor L. Szepesi \\ associate professor, Institute of Energy Engineering and Chemical Machinery, University of Miskolc \\ 3515 Miskolc, Miskolc-Egyetemváros, e-mail: szepesi@uni-miskolc.hu

\section{Zoltán Szamosi} \\ associate professor, Institute of Energy Engineering and Chemical Machinery, University of Miskolc \\ 3515 Miskolc, Miskolc-Egyetemváros, e-mail:vegyszam@uni-miskolc.hu
}

\begin{abstract}
Solid biofuels such as woodchips have always been a significant source of fuel in the field of renewable energy. However, the drying of wood chips has been a challenge in preparing biofuels and other applications. The moisture content of below 25\% in the wood chips of grade EN 14961 is considered the premium wood chip material. Solar drying emerged as a leading solution for the drying of wood chips. The paper investigates the comparison of moisture removal rate using a natural convective solar dryer compared to open sun drying developed at Miskolc, Hungary $\left(48^{\circ} 06^{\prime} 15.0^{\prime \prime} \mathrm{N}\right.$ $20^{\circ} 47^{\prime} 30.0^{\prime \prime} E$ ).
\end{abstract}

Keywords: drying, wood chips, moisture content

\section{Introduction}

The wood as a forest-based product is a significant contribution as a solid fuel to biomass energy production. The European Union EU countries are bound to see an increase in renewable energy sources using RES to curb carbon emissions.[1] The EU countries have been and continue to be a significant global contributor of wood as biomass fuel for power generation.[2] The interrelation of carbon emissions and RES. The study suggests that for EU nations, the correlation between RES and economic growth of nations is higher in high gross development product GDP countries than in low GDP countries.[3]Recent research findings estimate that woody biomass has promising prospects in the coming decades with reduced carbon emissions. [4] The research prediction for 2050 suggests (0-165 EJ/year) consumption of wood biomass with a price range of $(0-30 \$ / G J)$ can substitute $2-18 \%$ of global primary energy consumption on earth.[5] The wood chip's combustion properties should be intact thoroughly to make the optimum use of these predictions. Thus, proper drying or moisture removal from the wood material becomes an inevitable process. Hybrid solar drying with phase change material and various modelling techniques emerged as a promising solution to agriculture and forest-based products.[6][7] Data from EUROSTAT reveals that renewable energy consumption grew by $78.6 \%$ among the EU countries. This growth was noticed for the duration between 2005-2016. 


\section{Drying of wood chips}

For proper utilization of biomass, the wood material must be dried adequately to enhance its calorific value. The wood is majorly used as biomass and, most of the time, in chip forms. The forest residuals are collected in the form of big log heads of trees.[8] These log heads are crushed as chips for various applications, mostly gasification. The fresh logs from forests sometimes have water content beyond $70 \%$. This water absorption makes it completely useless in gasification and other heat-generating applications. Thus, the drying of these wood chips becomes an inevitable part of the process. To enhance energy efficiency and reduce the load on gasification, a good calorific value must be maintained in the process. This could only be achieved by optimum moisture removal from the wood. The optimization of moisture content also depends on the application of the product. According to the European Union standards for wood chips, the moisture content should be below 25\%, and for biomass to produce pellets, it should be less than 10\%.[9]Drying also requires some pre-treatments, especially in wood, for various applications - some of the standard practices pre-soaking, preheating, end coating, and warp control. Pre-soaking is done to keep the essence of the wood, for example, color and odor. Preheating is done chiefly commercially for improvement in permeability of the wood matter by using saturated steam. End coating prevents the product quality by ensuring the smoothness of the product. Warp is a sort of distortion, and sometimes it's a pre-treatment to check the distortion in the product.[10]

Moisture in the wood of any form consists of two parts: the free water detached from the cell wall, and the other is bound water in which water is stuck with the cell walls. The simple way to know moisture content on a dry basis can be found with the formula below:

$$
\mathrm{X}=\frac{\text { Mass of Water }}{\text { Oven Dry Mass }}
$$

The hygroscopic nature of the wood varies from type to type. The "bound water" inside cell walls is highly reflective of the hygroscopic nature of the wood. For "free water," the characteristics such as density, viscosity, vapor pressure, etc., are similar to regular water. Hence the behaviour of free water is quite predictable in nature. The simulations of the drying process are very critical in understanding the drying behaviour of the wood chips. Several macroscopic level equations govern the drying process, but they vary with the combination of state variables utilized in the study. Some of the common combinations are as below: [11]

- Only on Moisture content level (Saturation)

- Moisture content and Temperature (Enthalpy)

- Moisture content, temperature, and Gaseous pressure

The only moisture content-based model is the simplest way of analysis and is mostly done to understand the wood material's basic drying behaviour. The second type of research should be used where the temperature plays a critical role in the drying process. Its recommended for industrial or commercial studies. The third combination is only for detailed analyses. The models in which the internal gaseous pressure has a direct effect on moisture movement.

Low-temperature convective drying is the most common practice in the commercial wood drying sector. Understanding the basic physical behaviour of wood chips could be related to two steps. In the first step, the constant drying rate is observed, and the second phase is of decreasing drying stage. The two-staged process detail is depicted in Figure 1 and Figure 2, respectively. 


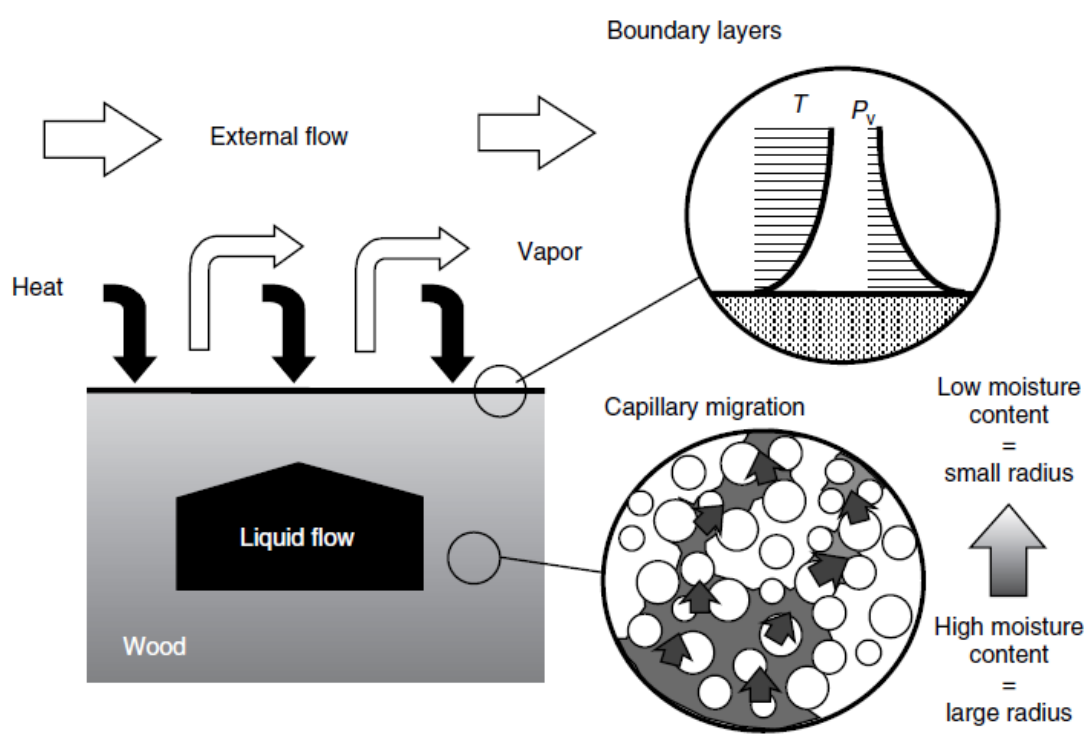

Figure 1. Insights during constant drying rate [11]

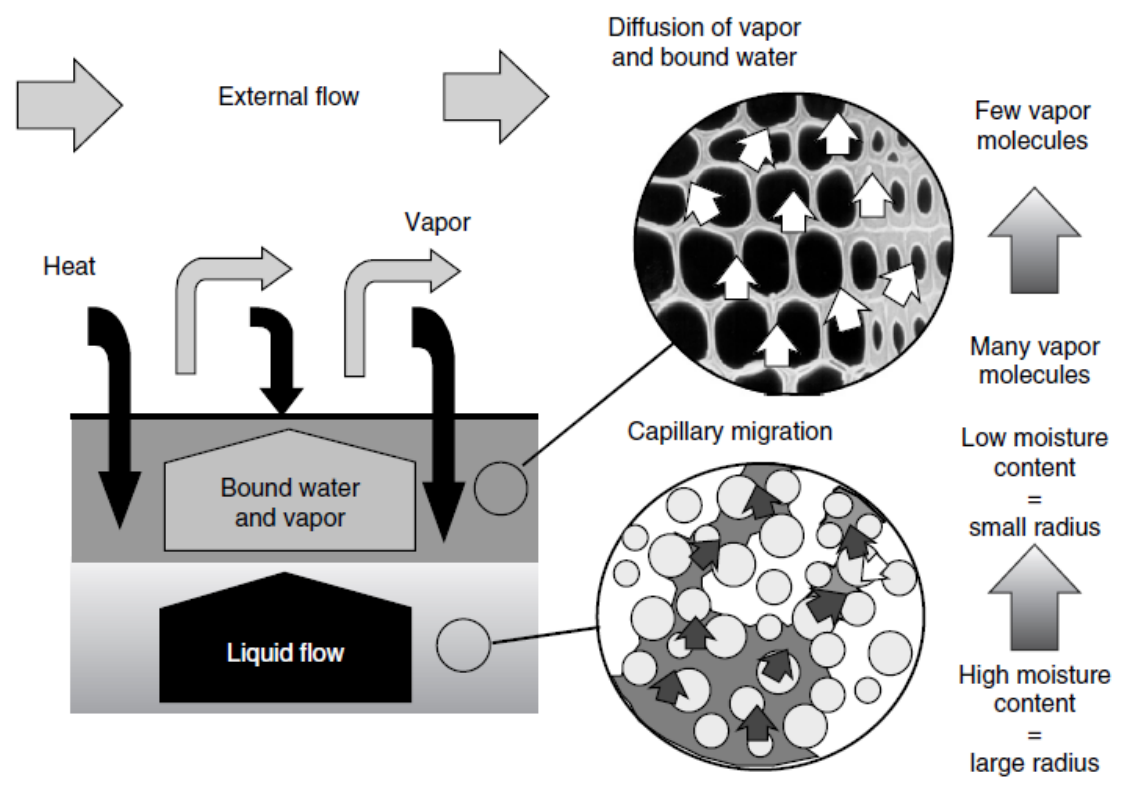

Figure 2. Insights during decreasing drying rate [11]

During the constant drying period, the moisture movement occurs due to capillary forces. In this period, evaporation occurs with dynamic equilibrium inside the boundary walls. In the second stage, when it's decreasing the drying rate, the wood's hygroscopic nature comes into play. In this region, the bound water vaporization takes place on a partial basis. Henceforth, heat flux is pushed through conduction in the cell walls' inner parts for enhancing heat transfer. 


\section{Materials and Method}

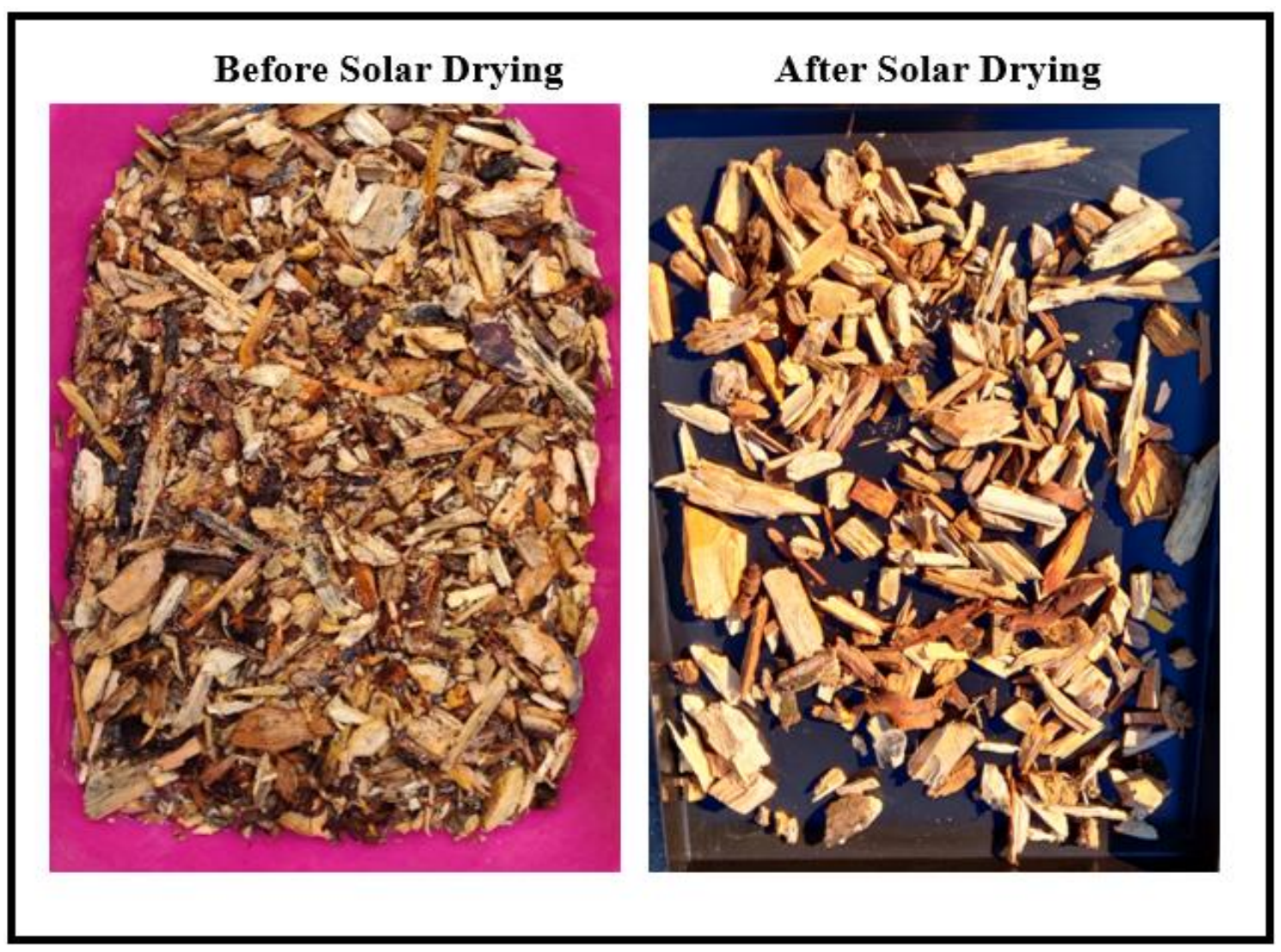

Figure 3. The mixture of various shapes and sizes of wood chips before and after observation

During experiments, various shapes and sizes of the wood chips of grade EN14961 were used in the laboratory. EN14961 is the European grade of solid biomass fuel utilized for various industrial as well as Nonindustrial applications. The moisture content measurement was done using lab-scale moisture measuring instrument. These woodchips are readily available around the forest regions of Miskolc city. The woodchips were pre-soaked for $24 \mathrm{Hrs}$ before sun-drying the chips in a box-type dryer developed at laboratory itself.

\section{Observations:}

The experiments were carried out on two different conditions (a) open sun drying of the chips (b) Drying inside the box type solar dryer. The moisture measuring device works with a sample of below 5 grams capacity. Hence different hourly samples were placed to notice the moisture removal with a percentage drop. The experiments were carried out for four different days to understand the drop behaviour. The behaviour analysis is depicted through graphical representation in the below-mentioned Figure 4 and Figure 5. 


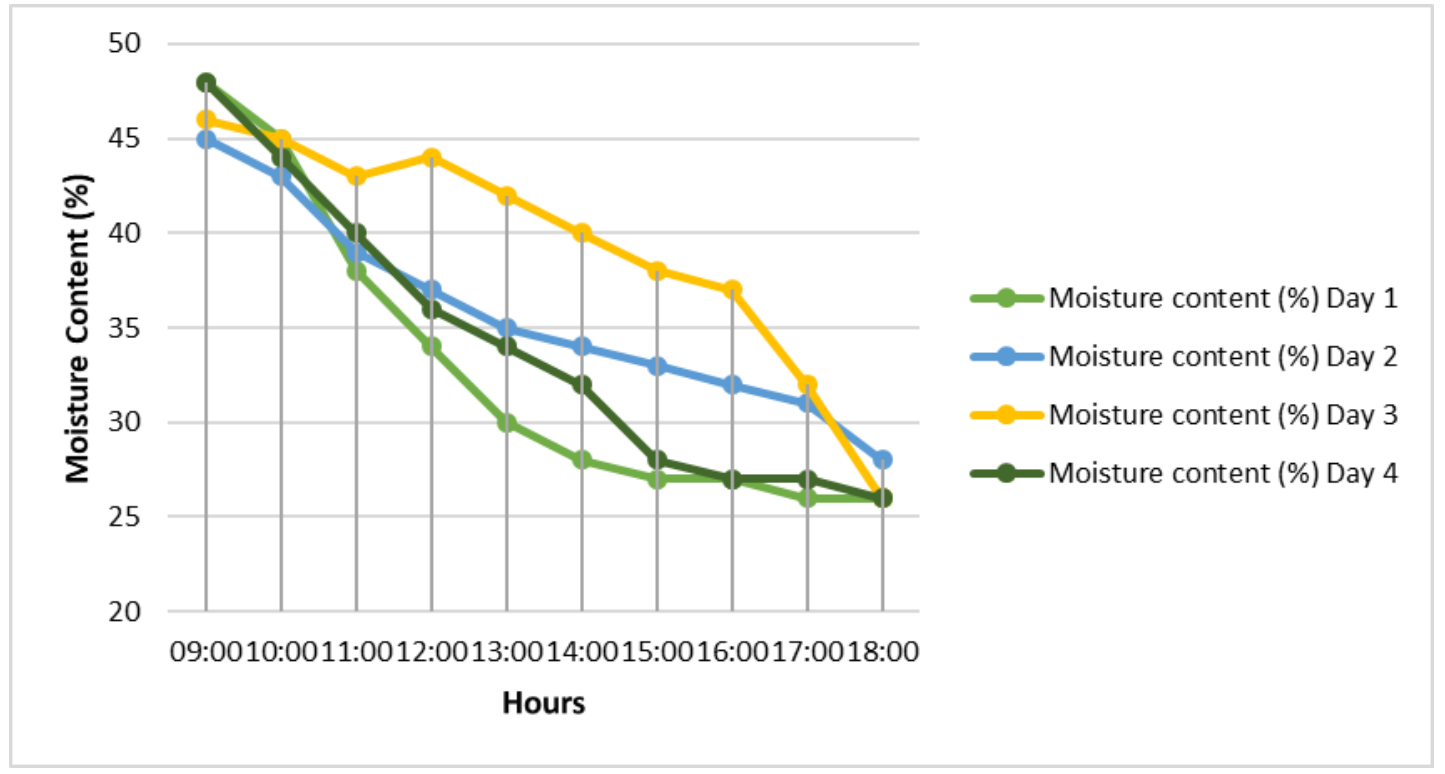

Figure 4. Moisture content decline graph for Natural convective solar dryer

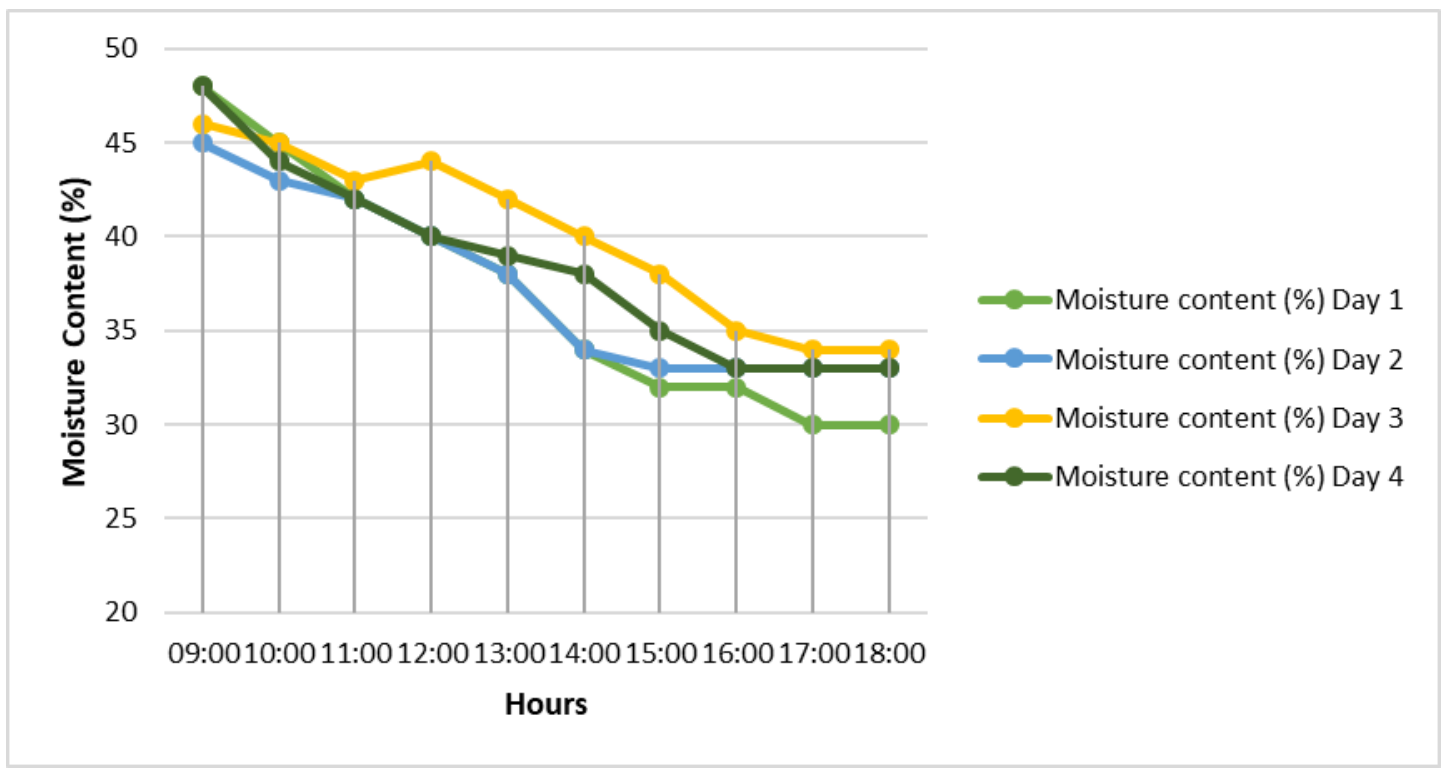

Figure 5. Moisture content decline graph for Open sun drying

\section{Conclusion}

The comparison graph reveals insights about the drying behaviour of wood chips. These wood chips have several applications. Mostly they are used as solid biomass fuel in large quantities for gasification purposes. Some of the points understood by this study are mentioned discussed below. 
In the case of open sun drying, it was observed that the moisture content didn't go below $30 \%$ moisture content. The natural convective solar dryer produced better results and reached the moisture content of around $25 \%$. It is recommended to use a solar cabinet dryer for achieving better results. Continuous drying, even during night hours, could be achieved by hybridizing the dryer with a latent heat source to supply heat in the evening hours.

\section{Reference}

[1] L. I. Cioca, L. Ivascu, E. C. Rada, V. Torretta, and G. Ionescu, "Sustainable development and technological impact on CO2 reducing conditions in Romania," Sustain., vol. 7, no. 2, pp. 1637-1650, 2015, https://doi.org/10.3390/su7021637

[2] European Commission, "Commission staff working document - impact assessment, part 3. Accompanying the document Proposal for a Directive of the European Parliament and of the Council on the promotion of the use of energy from renewable sources," 2016, pp. 1-5, 2016.

[3] S. Ntanos et al., "Renewable energy and economic growth: Evidence from European countries," Sustain., vol. 10, no. 8, pp. 1-13, 2018, https://doi.org/10.3390/su10082626

[4] C. Sulaiman, A. S. Abdul-Rahim, and C. A. Ofozor, "Does wood biomass energy use reduce CO2 emissions in European Union member countries? Evidence from 27 members," J. Clean. Prod., vol. 253, p. 119996, 2020, https://doi.org/10.1016/j.jclepro.2020.119996

[5] P. Lauri, P. Havlík, G. Kindermann, N. Forsell, H. Böttcher, and M. Obersteiner, "Woody biomass energy potential in 2050," Energy Policy, vol. 66, pp. 19-31, 2014, https://doi.org/10.1016/j.enpol.2013.11.033

[6] M. C. Ndukwu and L. Bennamoun, "Potential of integrating Na2SO4 $10 \mathrm{H} 2 \mathrm{O}$ pellets in solar drying system," Dry. Technol., vol. 36, no. 9, pp. 1017-1030, 2018, https://doi.org/10.1080/07373937.2017.1366506

[7] O. Prakash, V. Laguri, A. Pandey, A. Kumar, and A. Kumar, "Review on various modelling techniques for the solar dryers," Renew. Sustain. Energy Rev., vol. 62, pp. 396-417, 2016, https://doi.org/10.1016/j.rser.2016.04.028

[8] F. Simon, A. Girard, M. Krotki, and J. Ordoñez, "Modelling and simulation of the wood biomass supply from the sustainable management of natural forests," J. Clean. Prod., vol. 282, 2021, https://doi.org/10.1016/j.jclepro.2020.124487

[9] K. Klavina, A. Zandeckis, C. Rochas, and A. Zagorskis, "Low Temperature Drying As a Solution for Sustainable Use of Biomass," no. April, pp. 1-7, 2014

[10] G. Lianbai, "Recent research and development in wood drying technologies in China," Dry. Technol., vol. 25, no. 3, pp. 463-469, 2007, https://doi.org/10.1080/07373930601183900

[11] A. Mujumdar, P. Perré, and R. Keey, "Drying of Wood: Principles and Practices," Handb. Ind. Drying, Fourth Ed., no. July, pp. 797-846, 2014, https://doi.org/10.1201/b17208-44 